\title{
spotlight on dental practice managers
}

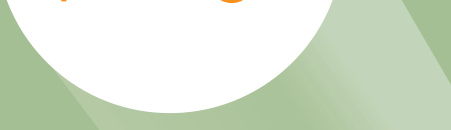

The British Dental Practice Managers' Association (BDPMA) receives many enquiries from dental practice managers (DPMs) regarding the most appropriate training and qualifications for them to pursue and whilst the Association would advocate a nationally-recognised generic business qualification as the most appropriate route for individuals seeking formal development, they would encourage all business professionals to immerse themselves in any form of continual professional development that results in their improved performance, increases their job satisfaction and fulfils their personal and professional ambitions.

\section{The formal development route - non-dental}

Institutions that offer general management qualifications usually offer a high standard of learning and although not dental-specific, they seek to provide the necessary skills to perform across any industry sector. They also cater to all levels of previous academic achievement so if managers haven't studied before, they can ease themselves in gently. The added advantage to this route is the interaction with managers from different industries. More information can be found

at www.management-standards.org.uk.

\section{Dental-specific courses}

According to the BDPMA, specifically tailored dental management courses have been met with mixed feeling from some members who have attended them whilst others have thoroughly enjoyed and benefited from them. The three best-known providers are as follows.

The Management School

Diploma in Professional Practice Management (Institute of Leadership \&

Management Level 5) - Various UK locations

www.themanagementschool.co.uk

Tel: 01823672622

UMD Professional Ltd

Diploma in Management (Institute of Leadership and Management Level 4)

Executive Diploma in Management (Institute of Leadership and Management Level

5) - Various UK locations

www.umdprofessional.co.uk

Tel: 02082552070

Dental Resource Company

BTEC Professional Diploma in Dental Practice Management (Level 4) - Various UK

locations or home study

www.dental-resource.co.uk

Tel: 08700664398

\section{CPD}

To keep your skills and knowledge fresh and up-to-date, the BDPMA recommends investigating the business section of your local bookstore or library. Useful books include The Quest Toolbox Series, the Dummies Guide books and the Virgin Business Guides. Attend as many workshops and seminars as you can; keep abreast of what is going on locally through your Chamber of Commerce and Business Link networks; attend BDPMA events and do some networking; and log onto the BDPMA's website at www.bdpma.org.uk to download a document called The competences of a dental practice manager which clearly identifies the skills necessary to progress in the DPM role. Members can also access the BDPMA's recommended annual pay scale which together with the competences document provides a clear and structured path for all DPMs to follow. The BDPMA can be contacted on 01844886364 or info@bdpma.org.uk.

\section{UPCOMING COURSES FOR DENTAL CARE PROFESSIONALS AT THE EASTMAN}

Hygienist-therapists 4-day Advanced Periodontal Instrumentation Course Covering all aspects of advanced non-surgical periodontal therapy Start dates: 28/09/07, 12/10/07, 09/11/07

Cost: $£ 788$

4-day hands-on Non-Surgical Periodontal Therapy Treatment of a Patient

Covering all aspects of advanced non-surgical periodontal therapy put into practice while treating a patient. Attending the above instrumentation course is a pre-requisite.

Start dates: 07/1 1/07, 21/11/07,

28/11/07, 23/01/08

Cost: $£ 1,200$

\section{Dental nurses}

Cross Infection Control

Course date (one full day): 14/01/08 Cost: $£ 73$

\section{Rubber Dam Course}

Course date (one full day): 31/01/08 Cost: $£ 73$

Draping for Implants

Course date (one full day): 08/02/08 Cost: $£ 91$

If you are interested in any of these courses at the Eastman please contact the course administrator Victoria Banks on 02089051251 orv.banks@eastman.ucl.ac.uk. 